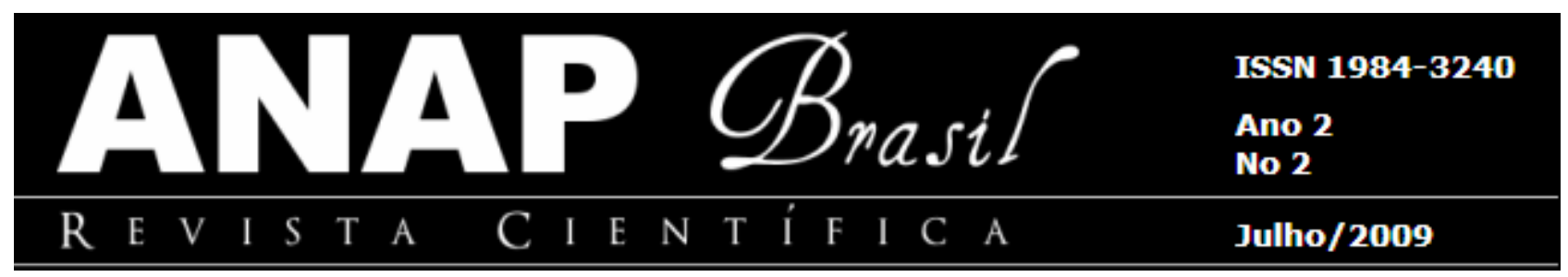

\title{
DIRETRIZES E PERSPECTIVAS DO LICENCIAMENTO AMBIENTAL
}

\section{Isabela Coelho Moreira ${ }^{1}$}

RESUMO: Na década de 70, iniciou-se a inclusão dos problemas ambientais no cenário econômico mundial como fator a ser considerado para o desenvolvimento dos países. No Brasil, a Política Nacional do Meio Ambiente foi instituída pela Lei no 6.938, em 1981, para controlar a preservação dos recursos naturais, na contrapartida do crescimento abrupto de empreendimentos e edificações. A legislação ambiental brasileira, embora densa, ainda encontra-se falha em alguns aspectos que são discutidos no presente estudo. Entretanto, as perspectivas para o aprimoramento e eficiência da aplicação destas leis tornam-se ascendentes diante do novo perfil da sociedade contemporânea do século XXI, que se preocupa, verdadeiramente, com os recursos e a qualidade ambiental.

Palavras-chave: Licenciamento ambiental. Direito ambiental. Política Nacional do Meio Ambiente.

\section{INTRODUÇÃO}

Desde a década de 80, o Brasil possui uma Política Nacional do Meio Ambiente que visa assegurar o desenvolvimento socioeconômico do país com objetivo de preservação, melhoria e recuperação da qualidade ambiental (BRASIL, 2007). Instituída pela Lei $n^{0}$ 6.938/81 esta política contribui como

${ }^{1}$ Bacharel em Ecologia - Centro Universitário de Belo Horizonte - UNI-BH. isabelacoelhomoreira@hotmail.com 
ferramenta de controle para a preservação dos recursos naturais, na contrapartida do crescimento abrupto de empreendimentos e edificações, que exploram e usufruem do meio ambiente, indevidamente.

Uma das ferramentas de contribuição gerada por esta Lei é o procedimento do Licenciamento Ambiental a que devem se submeter os empreendimentos considerados efetivos ou potencialmente poluidores ou daqueles que, sob qualquer forma, possam causar degradação ambiental (BRASIL, 2007). O Licenciamento visa assegurar 0 equilíbrio entre os objetivos do desenvolvimento socioeconômico e a preservação do meio ambiente. Este procedimento deve ser fiscalizado e controlado pelos devidos órgãos ambientais competentes a cada esfera de alcance. O Sistema Nacional de Meio Ambiente - SISNAMA, recente no Brasil, ainda é um sistema com lacunas, principalmente em relação ao ato de fiscalização e controle. Fato apontado por Agnes et. al. (2009) ao afirmar que o SISNAMA apresenta sobreposições e problemas de aplicação da legislação ambiental pela falta de foros adequados à resolução de impasses gerados por interesses conflitantes. Este fato decorre, principalmente, pela falta de equipe capacitada para atuar em consonância com o proposto pelas leis ambientais.

Vive-se, portanto, um conflito entre a estrutura proposta pelas leis ambientais brasileiras para a administração e controle do desenvolvimento econômico do país e a realidade da aplicação e fiscalização destas leis, diante de um cenário fragmentado e desordenado na estrutura organizacional da Política Nacional do Meio Ambiente.

Milaré (2004) ratifica esse ponto de vista ao apontar que há um desajuste entre as estruturas formais (legislação, planejamento e projetos governamentais) e as estruturas reais (divergências entre a administração pública e os segmentos de organizações particulares) no cenário brasileiro da política ambiental. Assim como é relevante constatar a estrutura organizacional das políticas ambientais brasileiras, é de suma importância avaliar o posicionamento ético dentro dos processos legais para consentir aos empreendimentos a licença ambiental. De acordo com Milaré, as abordagens da ética nestes procedimentos devem girar em torno de três aspectos:

a abordagem social do meio ambiente como patrimônio da coletividade, a perspectiva política do meio ambiente como objeto de gestão do Poder Público e o enfoque biocêntrico do meio ambiente como requisito de sobrevivência humana planetária. (MILARÉ, 2004, p. 88).

Portanto, o presente estudo objetiva apontar como se organizou a construção da política ambiental no Brasil e sua aplicação nos dias de hoje no âmbito jurídico - 
ambiental, para se fazer uma análise crítica do panorama atual, vislumbrando contribuir com uma nova perspectiva que incite a eficácia dos processos de licenciamento.

\section{METODOLOGIA}

O presente estudo realizou-se a partir da revisão bibliográfica das publicações científicas do âmbito jurídico e socioambiental através da busca de artigos científicos nas seguintes fontes: Revista de Direito Ambiental, Revista Eletrônica do Mestrado em Educação Ambiental, Revista Científica Eletrônica de Engenharia Florestal, além também de teses de mestrado e trabalhos apresentados em congressos da temática sobre meio ambiente e sustentabilidade. As palavras-chave buscadas foram: licenciamento ambiental, direito ambiental, Política Nacional do Meio Ambiente, meio ambiente, gestão ambiental, ética ambienta, ISO 14001, financiamento e responsabilidade socioambiental.

Foram utilizados, também, livros de coletâneas de publicações acerca do meio ambiente e suas interfaces como os livros: Meio Ambiente, desenvolvimento sustentável e políticas públicas, Previsão de Impactos, e Meio Ambiente no século XXI. Além das bibliografias recomendadas pelas disciplinas de Epistemologia Ambiental, Ecologia Humana e Avaliação do Impacto Ambiental do curso de Ecologia (UNI-BH) que contemplam as doutrinas do Direito Ambiental Brasileiro e sua legislação, dentre outras fontes complementares.

Por fim, procedeu-se a leitura minuciosa de 15 artigos científicos e 11 livros que abordam textos discursivos, teóricos, coletâneas de publicações, leis, decretos e resoluções. Realizou-se o fichamento deste material para desenvolver a elaboração de um texto discursivo acerca da temática do licenciamento ambiental no Brasil, baseandose na pesquisa realizada para refutar ou corroborar com os argumentos propostos.

\section{DESENVOLVIMENTO}

\subsection{HISTÓRICO DA TEMÁTICA AMBIENTAL}


O meio ambiente no século XXI tornou-se foco nos diversificados âmbitos da economia, educação, turismo e política, perdendo em certos momentos o foco, de fato, na questão ambiental. Para compreender e definir melhor a questão ambiental no momento atual de desenvolvimento da sociedade é importante considerar o histórico da relação homem - natureza desde o início das formações dos primeiros modelos de sociedade, pois a trajetória de socialização dos sujeitos e o conjunto de valores, crenças e ética, entre outros fatores, é o que orientam as escolhas do indivíduo e, portanto, as suas ações (ZHOURI, 2007). Desta forma, pode-se buscar justificativas para o comportamento do homem contemporâneo.

Gonçalves (1998, p. 32) afirma que "a problemática ecológica transita entre a Ciência, a Filosofia e a Política", logo para compreender e analisar a situação atual das relações entre o homem e o meio ambiente, faz-se necessária uma breve revisão da história.

Nas comunidades primórdias, formadas por indígenas e tribos, os povos eram adeptos do politeísmo, possuindo uma visão aproximada e integrada da natureza, posicionando-se como membro do meio ambiente, vivenciando como o oikos (do grego casa). Com o advento do pensamento judaico-cristão, surge um novo momento que demarca a relação de oposição entre homem-natureza, pois o homem passa a ser colocado como um ser dotado de privilégios, o ser criado a imagem e semelhança de Deus, e deriva-se deste pensamento o reducionismo da natureza, colocando-a como objeto de usufruto do homem (GONÇALVES, 1998).

A partir do século XV, com a introdução do Antropocentrismo, há uma supervalorização do homem que se distancia dos demais seres e, de certa maneira, posta-se diante deles em atitude de superioridade absoluta, abertamente antagônica (MILARÉ; COIMBRA, 2004). Já no século XVIII, surge a corrente cartesiana que segrega o conhecimento e valoriza a razão e o conhecimento técnico - científico. Neste momento, o pensamento cartesiano se evidencia com a Revolução Industrial e com a instituição do Capitalismo na sociedade, e assim a natureza ganhou status de matéria - prima inesgotável para a indústria produtiva. Neste seguimento caminhou-se até os dias atuais, em que a produção e o consumo proliferam de modo exacerbado com intuito de satisfazer uma sociedade insaciável, e como aponta Gonçalves (1998, p. 26), "em nossa sociedade a natureza é um objeto a ser dominado, sendo que a expressão dominar parte da premissa que o homem é não natureza".

Somente na década de 70, no Brasil, a questão ambiental passou a ser vista como problema ambiental. Como confirma Camargo, foi o início do despertar para 
o fato que estava esgotado o ciclo no qual a natureza era considerada um bem gratuito e substituível, com a capacidade de regeneração necessária para corrigir as devastações provocadas em nome da civilização e do progresso (CAMARGO, 2008, p. 308).

Introduzido o problema ambiental, surge no mundo, agora globalizado, a inserção da temática ambiental como fator coletivo e de responsabilidade de todos, e assim ocorreram as convenções mundiais em prol da melhoria da relação ser humano com o meio ambiente, acarretando o surgimento de novos conceitos ambientais acerca das ações e comportamentos da sociedade do século XX.

Em 1972, ocorreu a primeira conferência global voltada para o meio ambiente, a Conferência de Estocolmo, organizada pelo Organização das Nações Unidas - ONU, que segundo Magalhães apud MARTINS (2008), "trouxe novos conceitos de bem-estar para a humanidade e traçou o caminho a ser trilhado pela economia no futuro, dando à preservação ambiental uma dimensão universal".

É importante evidenciar que a década de 70 foi um período marcado pelo avanço econômico dos países em desenvolvimento, incluindo o Brasil. Desta forma, evidencia-se que as medidas propostas pelos países industrializados, como o documento The Limits to Growth ${ }^{2}$ para cessar o desenvolvimento das sociedades, direcionava a "culpa" da degradação ambiental aos países em franco crescimento, desviando o foco daqueles que já se encontravam em alto nível de ações impactantes ao ambiente (LAGO, 2007).

Vinte anos mais tarde, em 1992 ocorreu no Brasil a Conferência RIO 92 que chamou a atenção em todo o mundo com o novo ponto de vista que "os problemas ambientais do planeta estão intimamente ligados às condições econômicas e à justiça social" (TRIGUEIRO, 2008, p. 363). No evento foi acordada a proposta da Agenda 21, documento que traça as ações político-normativas a serem adotadas pelos Estados até o século XXI (MILARÉ, 1999). A realização desta conferência no Brasil tornou-se estratégica para chamar a atenção mundial para os países em desenvolvimento, apontando a nova perspectiva de que "o desenvolvimento sustentável seria a base e um novo paradigma da cooperação internacional” (LAGO, 2007, p.85).

Já em 2002, em Joanesburgo na Africa do Sul, ocorreu a RIO+10 com o objetivo principal de reforçar os compromissos políticos com o desenvolvimento sustentável. Neste

\footnotetext{
${ }^{2}$ Documento publicado poucos meses antes da Conferência de Estocolmo (março, 1972) que apresentava uma perspectiva apocalíptica das conseqüências do "progresso" nas bases em que se estava o desenvolvimento. O livro refletia a visão de que a sociedade moderna se encaminhava para a autodestruição (LAGO, 2007).
} 
momento, o Brasil se destacou por apresentar grandes progressos na área ambiental mesmo com suas dificuldades econômicas, com a desigualdade e a injustiça social (LAGO, 2001).

Diante das novas propostas e conceitos ambientais introduzidos no momento atual, observa-se a evolução dos meios organizacionais da sociedade e o acompanhamento dos instrumentos normativos legais para a nova questão ambiental, havendo portanto, a criação de uma legislação nacional visada para o meio ambiente e as relações do ser humano com o mesmo.

No cenário brasileiro, na década de 30 marcada pelo início da intensificação da industrialização, iniciou-se uma tímida legislação visada para os recursos naturais, porém estas leis possuiam o objetivo principal de regulamentar o acesso aos recursos e não a sua conservação. (SÁNCHEZ, 2008). De acordo com Crespo, no Brasil

\footnotetext{
a preocupação com o meio ambiente só começou a acontecer, timidamente, nos anos 60 e 70 , quando a sociedade urbanizada descobriu os efeitos colaterais da industrialização, tida naquele tempo como sinônimo de desenvolvimento (CRESPO, 2008, p. 60).
}

Nesta mesma época, em que enfim os problemas ambientais atingiram maior visibiliadade não somente para a sociedade, mas também para os governantes, foram criadas leis que se destinam as questões de poluição, planejamento territorial, e conservação. Portanto, impulsionada pelos princípios e proposições das conferências ambientais mundiais, na década de 80, foi instituída no Brasil a Política Nacional do Meio ambiente, destinada à conservação e preservação dos recursos naturais e das ações antrópicas impactantes à natureza, o que conferiu aos cidadãos e ao meio ambiente amparo legal do próprio Estado, sendo, de fato, um grande marco para o Direito Ambiental nacional (SIQUEIRA, 2002).

\subsection{LEGISLAÇÃO AMBIENTAL}

\subsubsection{A Política Nacional do Meio Ambiente - Lei no 6.938 / 1981 e Resolução CONAMA no 237/1997}

A Política Nacional do Meio Ambiente instituída pela Lei nº 6.938 de 31 de agosto de 1981, dispõe em seu artigo $2^{\circ}$ o objetivo de preservação, melhoria, e recuperação da 
qualidade ambiental propícia à vida, visando assegurar no país, condições ao desenvolvimento sócio-econômico, aos interesses da segurança nacional e à proteção da dignidade da vida humana (BRASIL, 2007).

Esta lei propiciou a criação do Sistema Nacional do Meio Ambiente - SISNAMA, que segmenta-se em órgãos de níveis federais, estaduais e municipais conferindo a estes a responsabilidade, fiscalização e controle das normas de políticas ambientais. Além desta organização, também foram criadas novas ferramentas para controle e fiscalização para os processos de desenvolvimento e atividades empresariais e suas implicações para o meio ambiente, surgindo, portanto na legislação brasileira os termos: Avaliação de Impacto Ambiental e Licenciamento Ambiental (SÁNCHEZ, 2008), sendo este último objeto de questionamento do presente estudo.

O licenciamento ambiental é definido no artigo $1^{\circ}$ da Resolução CONAMA no 237/97 como:

\footnotetext{
procedimento administrativo pelo qual o órgão ambiental competente licencia a localização, instalação, ampliação e a operação de empreendimentos e atividades utilizadoras de recursos ambientais, consideradas efetivas ou potencialmente poluidoras ou daquelas que, sob qualquer forma, possam causar degradação ambiental, considerando as disposições legais e regulamentares e as normas técnicas aplicáveis ao caso (CONAMA, 2008, p. 748).
}

O processo para o licenciamento é composto pela aquisição de três licenças, sendo estas a Licença Prévia (LP), para avaliar a viabilidade ambiental após estudos prévios e proposições de medidas para minimizar os impactos ambientais derivados do empreendimento; a Licença Instalação (LI), para que instalação do empreendimento seja realizada conforme os planos e medidas propostos em consonância com o diagnóstico ambiental realizado anteriormente; e por último, a Licença Operação (LO) que concede a permissão da operação da atividade de acordo com o cumprimento das proposições já feitas para um controle ambiental.

Um dos primeiros passos para iniciar a aquisição das licenças é a realização dos estudos ambientais que são compostos de um diagnóstico ambiental, abrangendo os meios biótico, fisco e sócio-econômico, análise dos impactos e suas alternativas, definição de medidas mitigadoras dos impactos negativos e a elaboração do programa de acompanhamento e monitoramento dos impactos (CONAMA, 2008).

É importante apontar que os estudos ambientais expressam tanto o interesse do empreendedor com o ponto de vista do desenvolvimento econômico, como também apresenta a realidade sócio-ambiental em que este se insere. Diante destas visões contrastantes, Milaré (2004) afirma que o estudo ambiental, mesmo sendo obrigatório por 
lei, traz implícito também um imperativo ético. É possível notar questões dúbias no ponto de vista da ética na elaboração dos estudos ambientais, pois a partir do momento que as medidas compensatórias ${ }^{3}$ propostas em estudos ambientais são de elevada importância para a aquiescência da licença ambiental, cabe ao empreendedor elaborar numerosos planos compensatórios ao invés de investir na mitigação dos impactos gerados pelo seu empreendimento.

Andrade e Romero (2005) afirmam que o foco da preservação ambiental tem uma inserção tardia no processo decisório de aprovação para conceder a licença, pois quando o empreendedor tem como prevenir os danos, há uma carência de propostas alternativas passando por justificador do empreendimento proposto por meio de um rol de medidas compensatórias ao invés de medidas que evitem ou minimizem os impactos. Assim surge o questionamento sobre a ética aplicada aos estudos ambientais: mitigar ou compensar?

Se não há uma condição específica na legislação atual vigente que pondere sobre a importância das medidas mitigadoras ${ }^{5}{ }^{4}$ sobre as compensatórias, torna-se permissivo para o empreendedor adotar medidas compensatórias que não irão contribuir, quanto menos minimizar o impacto causado in loco, e neste momento surge a relevância do princípio da ética ambiental perante os empreendimentos. Carneiro (2005) denomina estas ações como "jogo da mitigação" e a exemplo deste fato, o estudo de Prado Filho e Souza (2004) apresenta como é reduzido o número de medidas mitigadoras em relação ao número de impactos identificados nos estudos ambientais das mineradoras da região do Quadrilátero Ferrífero de Minas Gerais. Os autores também apontam que a apresentação destas medidas se faz, principalmente, pela preocupação do proponente do empreendimento em ver seu projeto aprovado pelo órgão ambiental, e não pela sua aplicação de fato. Logo, pode-se considerar que algumas medidas mitigadoras apenas constam nos estudos como estratégia de formalização para a licença ambiental requerida.

Outro aspecto questionador no campo dos estudos ambientais é o fato que a equipe técnica responsável pela elaboração destes estudos executa o trabalho "às expensas do empreendedor" (CONAMA,2008). Logo, não há investigação direta quanto a veracidade do diagnóstico ambiental realizado, podendo haver omissões de dados relevantes para a conservação de espécies, ecossistemas, e/ou patrimônios materiais e imateriais.

\footnotetext{
${ }^{3}$ Ações eu visam a compensar a perda de um bem ou função que será perdido em decorrência do projeto em análise.

${ }^{4}$ Ações propostas com a finalidade de reduzir a magnitude ou a importância dos impactos adversos (SANCHEZ, 2008).
} 
Milaré aponta a seguinte proposição como alternativa para esta questão:

Para atender a opção brasileira pela equipe multidisciplinar independente, poderse-ia pensar numa seleção pública, mediante licitação realizada pelo órgão ambiental, e cobrança ao proponente do projeto das despesas e custos referentes à realização do Estudo de Impacto Ambiental (MILARÉ, 2006, p.73).

É possível analisar também que, conferindo sequência ao processo de elaboração do Estudo de Impacto Ambiental - EIA, e seu respectivo Relatório de Impacto Ambiental RIMA, as realizações de audiências públicas são elaboradas para expor aos interessados o conteúdo dos estudos realizados, dirimindo dúvidas e recolhendo críticas e sugestões do público (CONAMA, 2008). Porém a própria legislação coloca que as audiências serão convocadas "quando couber, de acordo com a regulamentação pertinente", o que retira o caráter de obrigatoriedade deste procedimento.

Machado (2005) toca num ponto fundamental ao enfatizar que dar publicidade ao estudo ambiental transcende o conceito de possibilitar a leitura do mesmo, devendo o Poder Público levar as informações do estudo ao conhecimento público. Diante deste fato, é possível levantar mais questionamentos, pois a legislação ambiental brasileira é esparsa e apresenta outras formas de normas e atos administrativos (decretos, instruções normativas, etc), que podem refutar as leis, o que oportuniza ao empreendedor a escolha de qual norma cumprir adequando-a ao seu interesse. No caso do licenciamento ambiental existe uma série de resoluções que dispõem sobre este tema como é apresentado no Quadro 1.

Quadro 1 - Legislação sobre Licenciamento Ambiental

\begin{tabular}{|c|c|}
\hline Legislação & Definição \\
\hline $\begin{array}{l}\text { Resolução CONAMA } \\
\text { no 001, de 23/01/1986 }\end{array}$ & $\begin{array}{l}\text { Dispõe sobre critérios básicos e diretrizes gerais para } \\
\text { a avaliação de impacto ambiental. }\end{array}$ \\
\hline $\begin{array}{l}\text { Resolução CONAMA } \\
\text { no 006, de 24/01/1986 }\end{array}$ & $\begin{array}{l}\text { Dispõe sobre a aprovação de modelos para } \\
\text { publicação de pedidos de licenciamento. }\end{array}$ \\
\hline $\begin{array}{l}\text { Resolução, CONAMA } \\
\text { no } 009 \text { de 03/12/1987 }\end{array}$ & $\begin{array}{l}\text { Dispõe sobre a realização de Audiências Públicas no } \\
\text { processo de licenciamento ambiental. }\end{array}$ \\
\hline $\begin{array}{l}\text { Resolução CONAMA } \\
\text { no 11, de 04/05/1994 }\end{array}$ & Dispõe sobre alterações na Resolução nº 001/86. \\
\hline $\begin{array}{l}\text { Resolução CONAMA } \\
\text { no 237, de 19/12/1997 }\end{array}$ & $\begin{array}{l}\text { Dispõe sobre a revisão e complementação dos } \\
\text { procedimentos e critérios utilizados para o }\end{array}$ \\
\hline
\end{tabular}


\begin{tabular}{|l|l|}
\hline & licenciamento ambiental. \\
\hline
\end{tabular}

Fonte: CONAMA, 2008.

\subsubsection{O Sistema Nacional do Meio Ambiente - SISNAMA}

A aquisição das licenças ambientais é concedida pelos órgãos ambientais vigentes dependo do seu alcance. O empreendimento que ultrapassa os limites de um ou mais estados, são conferidos pelo órgão executor do SISNAMA, o Instituto Brasileiro de Meio Ambiente e Recursos Naturais Renováveis - IBAMA, já os empreendimentos que ocupam dois ou mais municípios de um mesmo estado são de competência do órgão ambiental estadual, e por fim, os empreendimentos que ocupam um único município será avaliado pela Secretaria Municipal do Meio Ambiente (CONAMA, 2008).

Em casos de licenciamento em nível municipal, de acordo com estudos realizados por Carvalho (2005), ocorre um despreparo dos setores ambientais municipais para responsabilizar-se pelos procedimentos do licenciamento ambiental. A autora expõe que seria ideal que cada município possuísse um Sistema Municipal de Meio Ambiente SISUMA seguindo os padrões do SISNAMA e coloca também que os municípios deveriam cuidar da disciplina do uso do solo com o intuito de mitigar todas as atividades no espaço urbano que provocam alterações no meio ambiente. Fato este que não ocorre em diversos municípios.

Novamente, nota-se a dificuldade no cumprimento da legislação ambiental, já que esta não é unificada, cabendo a cada instância criar e regulamentar suas diretrizes dentro da política ambiental. Desta forma, abre-se um campo permissivo ao poder público local em fazer prevalecer o que lhe confere maior interesse em termos econômicos. Deixando de lado os interesses da comunidade que não dispõe de uma política local efetiva, além, é claro, de não se focar nos impactos ambientais que poderão designar destas ações antiéticas. Portanto, são percebidos lacunas e descaminhos que fazem com que o processo do licenciamento ambiental brasileiro ainda seja permissivo com más condutas ambientais.

Ratificam esta idéia Santos e Japiassu (2006), ao afirmar que o licenciamento ambiental torna-se um instrumento vulnerável em face de suas características de detectar, monitorar, atenuar ou mesmo manipular os danos ambientais. Daí a forma de cominar com condutas éticas ou anti - éticas, dos agentes públicos, privados e outros 
envolvidos e interessados. E Milaré (2004) ainda acrescenta que, os preços desses pecados públicos, o pesado tributo social da degradação do meio ambiente será pago pelos mais fracos e pela própria natureza.

Portanto, compete ao SISNAMA o desafio de reger as políticas ambientais brasileiras com maior rigidez e orientar tanto os órgãos ambientais, como os investidores e as instituições envolvidas num empreendimento, para o cumprimento de ações e medidas que visem a preservação e a conservação ambiental como foco principal dos procedimentos do licenciamento ambiental, fato este que não condiz com a realidade atual.

\section{DESCAMINHOS DO LICENCIAMENTO AMBIENTAL}

\subsection{Instituições financeiras e certificações ambientais}

A premissa da busca pela melhoria da qualidade ambiental muitas vezes se perde no âmbito econômico, mesmo ao que tange os aspectos socioambientais. Pois, a procura e aquisição da licença ambiental, comumente, ocorrem com a finalidade de ascensão econômica/ financeira e não relaciona-se intrinsecamente ao fator meio ambiente. A realidade é que muitas empresa licenciam-se não pela preservação ambiental como ponto relevante, e sim pelos benefícios mercadológicos que uma empresa licenciada adquire no mercado.

A ponte de ligação entre o cenário econômico e o meio ambiente, faz-se através das relações entre investidores e empreendimentos que reconhecem a força mercadológica da postura "ambientalmente correta" perante aos consumidores. As instituições de financiamento também ocupam um importante papel nesta relação, pois empresas envolvidas em ações consideradas sustentáveis possuem uma imagem positiva e atendem a uma demanda, cujo perfil valoriza as ações socioambientais (BENVENUT; FUNK; FUNK, 2007). Este estreitamento de relações se justifica devido às proposições dos artigos 12 e 14, inciso III da Política Nacional do Meio Ambiente ao apontar que apenas empresas com licença ambiental poderão contar com financiamentos e incentivos governamentais (BRASIL, 2007).

Assim, o vínculo criado entre instituições bancárias e as questões ambientais se norteiam na análise de riscos (indiretos) em que o banco pode assumir ao ser 0 
intermediador financeiro, via operações de créditos ou como detentor de ativos financeiros de uma empresa, que poderá apresentar más condutas ambientais, acarretando uma série de perdas e punições por originar danos ambientais (BLANK; BRAUNER, 2009). Tosini (2005) acrescenta que o risco ambiental passou a ser risco financeiro para qualquer atividade econômica. Desta forma, a instituição bancária também poderá se incorporar a visibilidade ambiental negativa da empresa, ou seja, arcando como coresponsável das ações degradantes.

O mesmo ocorre na busca por certificações ambientais, como o ISO 14001, que se trata de um conjunto de normas e metodologias do Sistema de Gestão Ambiental - SGA para incluir ferramentas de gestão estratégica nas empresas e conquistar mais oportunidades e negociações financeiras. Afinal, mesmo sendo considerado uma forma de garantir o desenvolvimento sustentável e mobilizar organizações para a promoção de um meio ambiente ecologicamente equilibrado (FUCK; MENEZES; SIMÕES, 2009), as práticas de uma empresa certificada contribuem consideravelmente mais para o setor produtivo do que para o meio ambiente propriamente dito.

Por fim Viana et. al. conclui que

existe uma nítida interface entre o licenciamento e certificação ambiental, cuja verificação pode partir dos objetivos de ambos tendendo, em última análise, à conservação do meio ambiente e de serem meios para a condução dos processos produtivos sob o prisma do desenvolvimento sustentável, o que circunscreve a sua importância no âmbito econômico e social (VIANA et. al., 2003).

\subsection{Valores econômicos e valores sociais para a política ambiental}

Quando se trata os aspectos do licenciamento ambiental do ponto de vista da economia, é exercida a desmistificação desta prática como fator resolutivo para problemas ambientais. Infelizmente, por uma visão econômica estreita, o meio ambiente ainda é visto como fonte de matérias-primas escassas e de energia, bem como o receptor derradeiro dos dejetos da produção e do consumo (EL SERAFY, 2001). Porém, Sheng (2001) discorre sobre os valores econômicos, que segundo o autor, estão relacionados a valores sociais, como um subconjunto. E mesmo sendo os valores econômicos que ditam as atividades desempenhadas pelo homem, são os valores sociais que determinam as atitudes representativas e críticas para a solução dos problemas. Nesta linha de conceitos, cabe à sociedade a retomada da discussão e interiorização das questões 
ambientais como fator vitalício da permanência dos seres na Terra. E com esta proposição, torna-se mais acelerado o processo de amadurecimento e do aprimoramento das políticas em prol da melhoria da qualidade ambiental.

Para tanto, é importante considerar o quão necessário se fazem estas mudanças para que os rumos dos processos administrativos ambientais sejam realizados com seriedade e competência, a fim de desempenhar o proposto pela legislação ambiental brasileira, que mesmo com lacunas, impõe-se como satisfatória no quadro dos países em desenvolvimentos.

\section{CONSIDERAÇÕES FINAIS}

Ao perpassar pelos vários caminhos que transita a política ambiental brasileira, constata-se uma evolução da relevância do meio ambiente como fator intrínseco ao desenvolvimento econômico do país. A Política Nacional do Meio Ambiente se estabeleceu como diretriz para o desempenho das atividades econômicas, focando sempre a importância da proteção e da conservação da qualidade ambiental, além de estabelecer parâmetros para as relações desenvolvimentistas do campo da economia e dos recursos naturais que passaram a ser fatores preponderantes para possibilitar, ou não, a implantação de empreendimentos.

O licenciamento ambiental pode ser considerado o procedimento capaz de consolidar a aplicação de medidas sustentáveis em consonância com o desenvolvimento econômico do país, pois a Avaliação do Impacto Ambiental é o que torna possível as empresas atuarem coerentemente com as proposições da sustentabilidade, pois os diagnósticos ambientais e os programas de mitigação e/ou compensação, quando elaborados com real compromisso ético, social e ambiental, são as ferramentas que propiciam o equilíbrio entre as ações antrópicas e a conservação do meio ambiente. Mesmo que sejam constatados posturas anti-éticas e processos duvidosos no decorrer das ações que compõem o licenciamento ambiental, é de grande valia o crescimento das políticas ambientais brasileiras que permanecem em constante ascensão para melhor desempenhar as práticas de sustentabilidade. Outro ganho positivo que o licenciamento ambiental traz para o cenário ambiental é o princípio da co-responsabilidade, que incita nas empresas envolvidas com o empreendimento a tomada de ações e posturas voltadas, 
mesmo que indiretamente, para o meio ambiente, o que fortalece a corrente ambiental dentro do setor econômico.

É importante salientar que problemática ambiental se constrói quando ocorre a falta de compromisso socioambiental nas esferas que competem o poder de ação, ou seja, os órgãos ambientais e os empreendedores. A partir do momento que estes deixam prevalecer, exclusivamente, os valores econômicos nas tomadas de decisões, tornam-se permissivas ações que nem sempre contemplam o meio ambiente com a totalidade de seu valor. E como a legislação ambiental ainda é permissiva e fragmentada, é possível que ações sejam implantadas legalmente, no âmbito jurídico, mas que não correspondem aos princípios éticos ambientais.

Enfim, constata-se que o Brasil possui um grande potencial para dar um salto qualitativo em diversas áreas, inclusive na questão do licenciamento ambiental, devendo aliançar medidas de caráter ético, social, econômico e ambiental para fazer valer a máxima da legislação ambiental brasileira,

que todos têm direito ao meio ambiente ecologicamente equilibrado, bem de uso comum do povo e essencial à sadia qualidade de vida, impondo-se ao Poder público e à coletividade o dever de defendê-lo e preservá-lo para as presentes e futuras gerações (BRASIL, 2007, p.138). 


\section{REFERÊNCIAS}

AGNES, C. C.; CALEGARI, L.; GATTO, D. A.; STANGERLIN, D. M. Uma discussão sobre a descentralização da gestão ambiental. Revista Científica Eletrônica De Engenharia Florestal. São Paulo. n. 14. ago. 2009. Disponível em:

<http://www.revista.inf.br/florestal/pages/artigos/6.gestao\%20anbiental.pdf>Acesso em: 22 abr. 2009

ANDRADE, L. M. S., ROMERO, M. A. B. A importância das áreas ambientalmente protegidas nas cidades In: XI ENCONTRO NACIONAL DA ASSOCIAÇÃO NACIONAL DE PÓS - GRADUAÇÃO E PESQUISA EM PLANEJAMENTO URBANO E REGIONAL. 11. 2005. Salvador, BA.

BRASIL. Constituição (1988). Coletânea de legislação ambiental: atualizada até 16.01.2007. 6. ed. rev. ampl. organização: Odete Madauar. São Paulo: Revista dos Tribunais, 2007. 996p.

BLANK, D. M. P. ; BRAUNER, M. C. C. A responsabilidade civil ambiental das instituições bancárias pelo risco ambiental produzido por empresas financiadas. Revista Eletrônica do Mestrado em Educação Ambiental, v. 22, p. 261-275, 2009.

BENVENUTI, C.; FUNK, F.; FUNK, S. O eco-design das empresas em busca da sustentabilidade: premissa para a obtenção de crédito junto às instituições financeiras (bancos). In: I ENCONTRO DE SUSTENTABILIDADE EM PROJETO DO VALE DO JATAÍ. Balneário Camboriú. Anais do I Encontro de Sustentabilidade do Vale do Itajaí, 2007.

CAMARGO, A. Governança para o século 21. In: TRIGUEIRO, A. (Coord.). Meio ambiente no século 21: 21 especialistas falam da questão ambiental nas suas áreas de conhecimento.5 ed. Campinas: Armazém do Ipê, 2008. p. 306 - 312.

CARNEIRO, E. J. A oligarquização da "política ambiental" mineira. In: ZHOURI, A.; LASCHEKSKI K.; PEREIRA, D. B. A insustentável leveza da política ambiental: desenvolvimentos e conflitossocioambientais. Belo Horizonte: Autêntica, 2005. 287 p.

CARVALHO, M. A. Os Desafios do Licenciamento Ambiental Municipal. In: XIV CONGRESSO NACIONAL DO CONPEDI, 2005, Fortaleza. Anais do XIV Congresso Nacional do CONPEDI. Florianópolis: Fundação Boiteux, 2005.

CONSELHO NACIONAL DO MEIO AMBIENTE. Resoluções do CONAMA : resoluções vigentes publicadas entre julho de 1984 e novembro de 2008. 2 ed. Brasília: Conama, 2008. 928p.

CRESPO, S. Uma visão sobre a evolução da consciência ambiental no Brasil nos anos 1990. In: TRIGUEIRO, A. (Coord.). Meio ambiente no século 21: 21 especialistas falam da questão ambiental nas suas áreas de conhecimento.5 ed. Campinas: Armazém do Ipê, 2008. p. $59-73$.

EL SERAFY, S. Contabilidade verde e política económica. In: CAVALCANTI, C. (Org.). Meio ambiente, desenvolvimento sustentável e políticas públicas.3. ed. São Paulo: Cortez: Recife: Fundação Joaquim Nabuco, 2001. p. 193 -213. 
FUCK, H. Y. ; MENEZES, M. P.; SIMÕES, L. P. Requisitos de Sistema de Gestão ambiental com base na NBR ISO 14001:2004 e benefícios de sua implantação. 2009. Universidade Federal do Espírito Santo. Disponível em: <http://artigocientifico.uol.com.br/uploads/artc_1238795238_56.pdf>. Acesso em: 01 out. 2009.

GONÇALVES, C. W. P. Os (des)caminhos do meio ambiente. 6 ed. São Paulo: Contexto. 1998. 148p.

LAGO, A. A. C. Estocolmo, Rio, Joanesburgo. O Brasil e as três conferências ambientais das Nações Unidas. Brasília: Instituto Rio Branco. Fundação Alexandre e Gusmão, 2007. 276 p.

MACHADO, P. A. L. Direito ambiental brasileiro. 13. ed. São Paulo. Malheiros, 2005, $1092 \mathrm{p}$.

MARTINS, J. X. F. A importância dos princípios constitucionais ambientais na efetivação da proteção do meio ambiente. Revista Científica ANAP Brasil, Tupã. n.1, p. $34-52$, jul.2008.

MILARÉ, E. Direito do ambiente: um direito adulto. Revista de Direito Ambiental, São Paulo, ano 4, n. 15, p. 34-55, jul - set. 1999.

MILARÉ, E. Direito do Ambiente: doutrina, prática, jurisprudência, glossário. São Paulo: Revista dos Tribunais, 2001.

MILARÉ, E.; COIMBRA, J. A. A. Antropocentrismo x Ecocentrismo na ciência jurídica. Revista de Direito Ambiental, São Paulo: ed. RT (Revista dos Tribunais), n. 36, p.9 - 42, out.- dez. 2004.

MILARÉ, E. Estudo prévio de impacto ambiental no Brasil. In: AB'SABER, A.; MÜLLERPLANTENBERG, C. (Orgs.) Previsão de Impactos: O estudo de impacto ambiental no Leste, Oeste e Sul. Experiências no Brasil, na Rússia e na Alemanha. 2. ed. São Paulo: Editora da Universidade de São Paulo, 2006. p. 51 -83.

SÁNCHEZ, L. E. Avaliação do impacto ambiental: conceitos e métodos. São Paulo: Oficina de textos, 2008. 495p.

SANTOS, A. P. O.; JAPIASSÚ, M. C. Ética no licenciamento ambiental. In: CONGRESSO DE PESQUISA E INOVAÇÃO DA REDE NORTE NORDESTE DE EDUCAÇÃO TECNOLÓGICA. 1. 2006. Natal, RN.

SCHNEIDER, E. Gestão ambiental municipal: preservação ambiental e o desenvolvimento sustentável. Mestrado Interinstitucional PPGA - UNIVATES, 2001. Disponível em: http://www.seiam.ac.gov.br/curso/index>. Acesso em: 22 abr. 2009.

SIQUEIRA, A. B. O direito ambiental na legislação brasileira: um contributo para o resgate da história. Revista eletrônica do Mestrado em educação Ambiental, Rio Grande, v.9. p. 112-123. jul - dez. 2002.

SHENG, F. Valores em mudança e construção de uma sociedade sustentável. In: CAVALCANTI, C. (Org.). Meio ambiente, desenvolvimento sustentável e políticas públicas.3. ed. São Paulo: Cortez: Recife: Fundação Joaquim Nabuco, 2001. p. 165 178. 
TRIGUEIRO, A. (Coord.). Meio ambiente no século 21: 21 especialistas falam da questão ambiental nas suas áreas de conhecimento.5 ed. Campinas: Armazém do Ipê, 2008. $367 \mathrm{p}$.

TOSINI, M. F. C, Risco ambiental para as instituições financeiras bancárias. Unicamp, Campinas, 2005.

VIANA, E. C. et. al. Análise técnico-jurídica do licenciamento ambiental e sua interface com a certificação ambiental. Revista Árvores, Viçosa - MG, v. 27, n. 4, p. 587 - 595, 2003.

ZOURRI, A. Conflitos sociais e meio ambiente urbano. Comunidades, Meio ambiente e desenvolvimento. Dissertação (Mestrado). Universidade Federal do Rio de Janeiro, Rio de Janeiro, 2007. 